\title{
Fixed points of conditionally $F$-contractions in complete metric-like spaces
}

\author{
Erdal Karapınar ${ }^{1,2}$, Marwan A Kutbi $^{3^{*}}$, Hossein Piri ${ }^{4}$ and Donal O'Regan ${ }^{2,5}$
}

\author{
"Correspondence: \\ mkutbi@yahoo.com \\ ${ }^{3}$ Department of Mathematics, King \\ Abdulaziz University, P.O. Box 80203 , \\ Jeddah, 21589, Saudi Arabia \\ Full list of author information is \\ available at the end of the article
}

\begin{abstract}
In this paper, we introduce the notion of a conditionally F-contraction in the setting of complete metric-like spaces and we investigate the existence of fixed points of such mappings. Our results unify, extend, and improve several results in the literature.
\end{abstract}

MSC: $46 \mathrm{~T} 99 ; 47 \mathrm{H} 10 ; 54 \mathrm{H} 25 ; 54 \mathrm{E} 50$

Keywords: F-contraction; conditionally F-contraction; fixed point; metric-like spaces; partial metric space

\section{Introduction and preliminaries}

Recently, Wardowski [1] introduced the notion of a $F$-contraction mapping and investigated the existence of fixed points for such mappings. The results of Wardowski [1] extend and unify several fixed point results in the literature including the celebrated Banach contraction mapping principle.

In this paper, we present the notion of conditionally $F$-contractions of various types and we investigate the existence of a fixed point for such mappings in metric-like spaces. We also present some criteria for the uniqueness of a fixed point.

Throughout the paper, $\mathbb{N}$ and $\mathbb{N}_{0}$ denote the set of positive integers and the set of nonnegative integers. Similarly, let $\mathbb{R}, \mathbb{R}^{+}$and $\mathbb{R}_{0}^{+}$represent the set of reals, positive reals, and the set of nonnegative reals, respectively.

Definition 1.1 [1] Let $\mathcal{F}$ be the family of all functions $F:(0, \infty) \rightarrow \mathbb{R}$ such that

(F1) $F$ is strictly increasing, i.e. for all $x, y \in \mathbb{R}^{+}$such that $x<y, F(x)<F(y)$;

(F2) for each sequence $\left\{\alpha_{n}\right\}_{n=1}^{\infty}$ of positive numbers, $\lim _{n \rightarrow \infty} \alpha_{n}=0$ if and only if $\lim _{n \rightarrow \infty} F\left(\alpha_{n}\right)=-\infty ;$

(F3) there exists $k \in(0,1)$ such that $\lim _{\alpha \rightarrow 0^{+}} \alpha^{k} F(\alpha)=0$.

Definition 1.2 [1] Let $(X, d)$ be a metric space. A mapping $T: X \rightarrow X$ is said to be a $F$ contraction on $(X, d)$ if there exist $F \in \mathcal{F}$ and $\tau>0$ such that

$$
\forall x, y \in X, \quad[d(T x, T y)>0 \Rightarrow \tau+F(d(T x, T y)) \leq F(d(x, y))]
$$

Remark 1.3 From (F1) and (1) it is easy to conclude that every $F$-contraction is necessarily continuous.

(c) 2015 Karapınar et al. This article is distributed under the terms of the Creative Commons Attribution 4.0 International License (http://creativecommons.org/licenses/by/4.0/), which permits unrestricted use, distribution, and reproduction in any medium, provided you give appropriate credit to the original author(s) and the source, provide a link to the Creative Commons license, and indicate if changes were made. 
Recently, Piri and Kumam [2] extended the result of Wardowski [1] by replacing the condition (F3) in Definition 1.1 with the following one:

(F3') $F$ is continuous on $(0, \infty)$.

Let $\mathfrak{F}$ denote the family of all functions $F: \mathbb{R}_{+} \rightarrow \mathbb{R}$ which satisfy conditions (F1), (F2) and (F3').

Under this new set-up, they proved a fixed point result that generalized the result of Wardowski [1].

Definition 1.4 [2] Let $(X, d)$ be a metric space and let $F \in \mathfrak{F}$. A mapping $T: X \rightarrow X$ is said to be a $F$-Suzuki-contraction if there exist $F \in \mathfrak{F}$ and $\tau>0$ such that for all $x, y \in X$ with $T x \neq T y$

$$
\frac{1}{2} d(x, T x)<d(x, y) \quad \Rightarrow \quad \tau+F(d(T x, T y)) \leq F(d(x, y)) .
$$

Wardowski and Van Dung [3] introduced the notion of a $F$-weak contraction and proved a fixed point theorem for $F$-weak contractions.

Definition 1.5 [3] Let $(X, d)$ be a metric space. A mapping $T: X \rightarrow X$ is said to be a $F$ weak contraction on $(X, d)$ if there exist $F \in \mathcal{F}$ and $\tau>0$ such that, for all $x, y \in X$ satisfying $d(T x, T y)>0$, the following holds:

$$
\tau+F(d(T x, T y)) \leq F\left(\max \left\{d(x, y), d(x, T x), d(y, T y), \frac{d(x, T y)+d(y, T x)}{2}\right\}\right) .
$$

Wardowski and Van Dung [3] gave an example to show that their result was a proper extension of results in the literature.

There are many papers in the literature that generalize the notion of metric spaces as well as the Banach contraction mapping principle (see [4-11] and the references therein). The notion of a metric-like space was introduced by Hitzler [12] and re-introduced by Amini-Harandi in [13].

Definition 1.6 (See [12]) Let $X$ be a non-empty set. A mapping $d: X \times X \rightarrow \mathbb{R}_{0}^{+}$is said to be a metric-like (dislocated) on $X$, if for all $x, y, z \in X$ the following conditions are satisfied:

(D1) if $d(x, y)=0$ then $x=y$.

(D2) $d(x, y)=d(y, x)$.

(D3) $d(x, y) \leq d(x, z)+d(z, y)$.

The pair $(X, d)$ is called a dislocated (metric-like) space.

Notice that if we replace the condition (D3) with

(D3*) $d(x, y) \leq d(x, z)+d(z, y)-d(z, z)$

in Definition 1.6 then, $(X, d)$ turns to be a partial metric space (PMS). Fore more details see e.g. [14-18].

Remark 1.7 (See [13]) Every partial metric is metric-like (dislocate). 
A sequence $\left\{x_{n}\right\}_{n=1}^{\infty}$, in a metric-like space $(X, d)$,

(a) converges to $x \in X$ if $\lim _{n \rightarrow \infty} d\left(x_{n}, x\right)=d(x, x)$,

(b) is called Cauchy in $(X, d)$, if $\lim _{n, m \rightarrow \infty} d\left(x_{n}, x_{m}\right)$ exists and is finite.

A metric-like space $(X, d)$ is said to be complete if and only if every Cauchy sequence $\left\{x_{n}\right\}_{n=1}^{\infty}$ in $X$ converges to $x \in X$ so that

$$
\lim _{n, m \rightarrow \infty} d\left(x_{n}, x_{m}\right)=\lim _{n \rightarrow \infty} d\left(x_{n}, x\right)=d(x, x)
$$

We recall some basic definitions and crucial results on the topic. In this paper, we follow the notation of Amini-Harandi [13].

Definition 1.8 (See [13]) Let $(X, d)$ be a metric-like space and let $U$ be a subset of $X$. We say $U$ is a $d$-open subset of $X$, if for all $x \in X$ there exists $r>0$ such that $B_{d}(x, r) \subseteq U$. Also, $V \subseteq X$ is a $d$-closed subset of $X$ if $(X \backslash V)$ is a $d$-open subset of $X$.

Lemma 1.9 (See [19]) Let $(X, d)$ be a metric-like space. Then:

(A) if $d(x, y)=0$ then $d(x, x)=d(y, y)=0$;

(B) if $\left\{x_{n}\right\}$ be a sequence such that $\lim _{n \rightarrow \infty} d\left(x_{n}, x_{n+1}\right)=0$, then we have,

$$
\lim _{n \rightarrow \infty} d\left(x_{n}, x_{n}\right)=\lim _{n \rightarrow \infty} d\left(x_{n+1}, x_{n+1}\right)=0
$$

(C) if $x \neq y$ then $d(x, y)>0$;

(D) $d(x, x) \leq \frac{2}{n} \sum_{i=1}^{i=n} d\left(x, x_{i}\right)$ holds for all $x_{i}, x \in X$ where $1 \leq i \leq n$;

(E) if $\left\{x_{n}\right\}$ is a sequence in a $d$-closed subset $V$ of $X$ with $x_{n} \rightarrow x$ as $n \rightarrow \infty$, then $x \in V$;

(F) if $\left\{x_{n}\right\}$ is a sequence in $X$ such that $x_{n} \rightarrow x$ as $n \rightarrow \infty$ and $d(x, x)=0$, then $\lim _{n \rightarrow \infty} d\left(x_{n}, y\right)=d(x, y)$ for all $y \in X$.

Definition 1.10 Let $(X, d)$ and $(Y, \rho)$ be metric-like spaces and $\left\{x_{n}\right\}_{n=1}^{\infty}$ be a sequence in $X$ such that $x_{n} \rightarrow x$. A mapping $f: X \rightarrow Y$ is said to be continuous at a point $x \in X$ if $f\left(x_{n}\right) \rightarrow f(x)$

\section{Main results}

We begin this section with the following definition.

Definition 2.1 Let $(X, d)$ be a metric-like space. A mapping $T: X \rightarrow X$ is said to be a conditionally $F$-contraction of type (A) if there exist $F \in \mathfrak{F}$ and $\tau>0$ such that, for all $x, y \in X$ with $d(T x, T y)>0$,

$$
\frac{1}{2} d(x, T x)<d(x, y) \quad \Rightarrow \quad \tau+F(d(T x, T y)) \leq F\left(M_{T}(x, y)\right)
$$

where

$$
M_{T}(x, y) \max \left\{d(x, y), d(x, T x), d(y, T y), \frac{d(x, T y)+d(y, T x)}{4}\right\} .
$$

Theorem 2.2 Let $(X, d)$ is a complete metric-like space. If $T$ is a conditionally Fcontraction of type (A), then $T$ has a fixed point $x^{*} \in X$. 
Proof Take $x \in X$ and construct a sequence $\left\{x_{n}\right\}$ as follows:

$$
x_{n}=T x_{n-1}=T^{n} x \quad \text { for all } n \in \mathbb{N} \text { where } x_{0}=x .
$$

If there exists $n_{*} \in \mathbb{N}$ such that $d\left(x_{n_{*}}, T x_{n_{*}}\right)=0$ then $x_{*}=x_{n_{*}}$ becomes a fixed point which completes the proof. Consequently, in the rest of the proof, we assume that, for every $n \in \mathbb{N}$,

$$
0<d\left(x_{n}, T x_{n}\right)
$$

Hence, from (5), we have

$$
\frac{1}{2} d\left(x_{n}, T x_{n}\right)<d\left(x_{n}, T x_{n}\right) \quad \text { for all } n \in \mathbb{N} \text {. }
$$

Since $T$ is conditionally $F$-contraction (note $d\left(T x_{n}, T\left(T x_{n}\right)\right)=d\left(x_{n+1}, T x_{n+1}\right)>0$ ), from the inequality (6), we have

$$
\begin{aligned}
\tau+F\left(d\left(T x_{n}, T^{2} x_{n}\right)\right) \leq & F\left(\operatorname { m a x } \left\{d\left(x_{n}, T x_{n}\right), d\left(x_{n}, T x_{n}\right), d\left(T x_{n}, T^{2} x_{n}\right),\right.\right. \\
& \left.\left.\frac{d\left(x_{n}, T^{2} x_{n}\right)+d\left(T x_{n}, T x_{n}\right)}{4}\right\}\right) \\
\leq & F\left(\operatorname { m a x } \left\{d\left(x_{n}, T x_{n}\right), d\left(T x_{n}, T^{2} x_{n}\right),\right.\right. \\
& \left.\left.\frac{d\left(x_{n}, T x_{n}\right)+d\left(T x_{n}, T^{2} x_{n}\right)+d\left(T x_{n}, x_{n}\right)+d\left(x_{n}, T x_{n}\right)}{4}\right\}\right) \\
= & F\left(\operatorname { m a x } \left\{d\left(x_{n}, T x_{n}\right), d\left(T x_{n}, T^{2} x_{n}\right),\right.\right. \\
& \left.\left.\frac{3 d\left(x_{n}, T x_{n}\right)+d\left(T x_{n}, T^{2} x_{n}\right)}{4}\right\}\right) \\
= & F\left(\max \left\{d\left(x_{n}, T x_{n}\right), d\left(T x_{n}, T^{2} x_{n}\right)\right\}\right) .
\end{aligned}
$$

If there exists $n \in \mathbb{N}$ such that $\max \left\{d\left(x_{n}, T x_{n}\right), d\left(T x_{n}, T^{2} x_{n}\right)\right\}=d\left(T x_{n}, T^{2} x_{n}\right)$, then (7) becomes

$$
\tau+F\left(d\left(T x_{n}, T^{2} x_{n}\right)\right) \leq F\left(d\left(T x_{n}, T^{2} x_{n}\right)\right)
$$

which is a contradiction. Thus, we conclude that

$$
\max \left\{d\left(x_{n}, T x_{n}\right), d\left(T x_{n}, T^{2} x_{n}\right)\right\}=d\left(x_{n}, T x_{n}\right),
$$

for all $n \in \mathbb{N}$. Hence, the inequality (7) turns into

$$
F\left(d\left(T x_{n}, T^{2} x_{n}\right)\right) \leq F\left(d\left(x_{n}, T x_{n}\right)\right)-\tau \quad \text { for all } n \in \mathbb{N},
$$


which is equivalent to

$$
F\left(d\left(x_{n+1}, T x_{n+1}\right)\right) \leq F\left(d\left(x_{n}, T x_{n}\right)\right)-\tau \text { for all } n \in \mathbb{N} .
$$

Iteratively, we find that

$$
\begin{aligned}
F\left(d\left(x_{n}, T x_{n}\right)\right) & \leq F\left(d\left(x_{n-1}, T x_{n-1}\right)\right)-\tau \\
& \leq F\left(d\left(x_{n-2}, T x_{n-2}\right)\right)-2 \tau \\
& \leq F\left(d\left(x_{n-3}, T x_{n-3}\right)\right)-3 \tau \\
& \vdots \\
& \leq F\left(d\left(x_{0}, T x_{0}\right)\right)-n \tau .
\end{aligned}
$$

From (9), we obtain $\lim _{m \rightarrow \infty} F\left(d\left(x_{n}, T x_{n}\right)\right)=-\infty$, which together with (F2) gives

$$
\lim _{n \rightarrow \infty} d\left(x_{n}, T x_{n}\right)=\lim _{m \rightarrow \infty} d\left(x_{n}, x_{n+1}\right)=0 .
$$

Now, we claim that

$$
\lim _{n, m \rightarrow \infty} d\left(x_{n}, x_{m}\right)=0
$$

Arguing by contradiction, we assume that there exist $\epsilon>0$ and sequences $\{p(n)\}_{n=1}^{\infty}$ and $\{q(n)\}_{n=1}^{\infty}$ of natural numbers such that

$$
p(n)>q(n)>n, \quad d\left(x_{p(n)}, x_{q(n)}\right) \geq \epsilon, \quad d\left(x_{p(n)-1}, x_{q(n)}\right)<\epsilon \quad \text { for all } n \in \mathbb{N} .
$$

From the triangle inequality, we get

$$
\begin{aligned}
\epsilon & \leq d\left(x_{p(n)}, x_{q(n)}\right) \leq d\left(x_{p(n)}, x_{p(n)-1}\right)+d\left(x_{p(n)-1}, x_{q(n)}\right) \\
& \leq d\left(x_{p(n)}, x_{p(n)-1}\right)+\epsilon \\
& =d\left(x_{p(n)-1}, T x_{p(n)-1}\right)+\epsilon \quad \text { for all } n \in \mathbb{N} .
\end{aligned}
$$

Thus from (10), (13), and the sandwich theorem, we get

$$
\lim _{n \rightarrow \infty} d\left(x_{p(n)}, x_{q(n)}\right)=\epsilon
$$

Again by the triangle inequality, for all $n \in \mathbb{N}$, we have the following two inequalities:

$$
d\left(x_{p(n)}, x_{q(n)}\right) \leq d\left(x_{p(n)}, x_{p(n)+1}\right)+d\left(x_{p(n)+1}, x_{q(n)+1}\right)+d\left(x_{q(n)+1}, x_{q(n)}\right)
$$

and

$$
d\left(x_{p(n)+1}, x_{q(n)+1}\right) \leq d\left(x_{p(n)+1}, x_{p(n)}\right)+d\left(x_{p(n)}, x_{q(n)}\right)+d\left(x_{q(n)}, x_{q(n)+1}\right) .
$$


Letting $n \rightarrow \infty$ in the inequalities (15) and (16), using (10) and (14), we obtain

$$
\lim _{n \rightarrow \infty} d\left(x_{p(n)+1}, x_{q(n)+1}\right)=\epsilon .
$$

From (10) and (12), there exists $N_{2} \in \mathbb{N}$ such that

$$
\frac{1}{2} d\left(x_{p(n)}, T x_{p(n)}\right)<\frac{\epsilon}{2}<d\left(x_{p(n)}, x_{q(n)}\right), \quad \forall n>N_{2} .
$$

Note from (17) for $n$ large enough (i.e. $n \geq N_{3} \geq N_{2}$ say) we have $d\left(T x_{p(n)}, T x_{q(n)}\right)=$ $d\left(x_{p(n)+1}, x_{q(n)+1}\right)>0$. Since $T$ is a conditionally $F$-contractive mapping of type (A), we have (with $n \geq N_{3}$ )

$$
\begin{aligned}
\tau+ & F\left(d\left(T x_{p(n)}, T x_{q(n)}\right)\right) \\
\leq & F\left(\operatorname { m a x } \left\{d\left(x_{p(n)}, x_{q(n)}\right), d\left(x_{p(n)}, T x_{p(n)}\right), d\left(x_{q(n)}, T x_{q(n)}\right),\right.\right. \\
& \left.\left.\frac{d\left(x_{p(n)}, T x_{q(n)}\right)+d\left(x_{q(n)}, T x_{p(n)}\right)}{4}\right\}\right) \\
\leq & F\left(\operatorname { m a x } \left\{d\left(x_{p(n)}, x_{q(n)}\right), d\left(x_{p(n)}, T x_{p(n)}\right), d\left(x_{q(n)}, T x_{q(n)}\right),\right.\right. \\
& \left.\left.\frac{d\left(x_{p(n)}, T x_{p(n)}\right)+d\left(x_{q(n)}, T x_{q(n)}\right)+2 d\left(x_{q(n)}, x_{p(n)}\right)}{4}\right\}\right) \\
\leq & F\left(\operatorname { m a x } \left\{d\left(x_{p(n)}, x_{q(n)}\right), d\left(x_{p(n)}, T x_{p(n)}\right), d\left(x_{q(n)}, T x_{q(n)}\right),\right.\right. \\
& \left.\max \left\{d\left(x_{p(n)}, x_{q(n)}\right), d\left(x_{p(n)}, T x_{p(n)}\right), d\left(x_{q(n)}, T x_{q(n)}\right)\right\}\right) \\
= & F\left(\max \left\{d\left(x_{p(n)}, x_{q(n)}\right), d\left(x_{p(n)}, T x_{p(n)}\right), d\left(x_{q(n)}, T x_{q(n)}\right)\right\} .\right.
\end{aligned}
$$

Letting $n \rightarrow \infty$ in the inequality above and using (10), (14), and (F3') we obtain

$$
\tau+F(\varepsilon) \leq F(\varepsilon),
$$

a contradiction since $\tau>0$. Hence

$$
\lim _{m, n \rightarrow \infty} d\left(x_{n}, x_{m}\right)=0
$$

Therefore, we conclude that $\left\{x_{n}\right\}_{n=1}^{\infty}$ is a Cauchy sequence in $X$. Now $(X, d)$ is a complete metric-like space, so there exists $x^{*} \in X$ such that

$$
d\left(x^{*}, x^{*}\right)=\lim _{n \rightarrow \infty} d\left(x_{n}, x^{*}\right)=\lim _{n, m \rightarrow \infty} d\left(x_{n}, x_{m}\right)=0 .
$$

Now note

$$
\begin{aligned}
d\left(x^{*}, T x^{*}\right) & \leq d\left(x^{*}, x_{n+1}\right)+d\left(x_{n+1}, T x^{*}\right) \\
& \leq d\left(x^{*}, x_{n+1}\right)+d\left(x_{n+1}, x^{*}\right)+d\left(x^{*}, T x^{*}\right) \\
& =2 d\left(x^{*}, x_{n+1}\right)+d\left(x^{*}, T x^{*}\right) .
\end{aligned}
$$


Thus from (20) and the sandwich theorem, we get

$$
\lim _{n \rightarrow \infty}\left[d\left(x^{*}, x_{n+1}\right)+d\left(x_{n+1}, T x^{*}\right)\right]=d\left(x^{*}, T x^{*}\right) .
$$

Now this and (20) yield

$$
\lim _{n \rightarrow \infty} d\left(x_{n+1}, T x^{*}\right)=d\left(x^{*}, T x^{*}\right)
$$

We now prove that, for every $n \in \mathbb{N}$,

$$
\frac{1}{2} d\left(x_{n}, T x_{n}\right)<d\left(x_{n}, x^{*}\right) \quad \text { or } \quad \frac{1}{2} d\left(T x_{n}, T^{2} x_{n}\right)<d\left(T x_{n}, x^{*}\right), \quad \forall n \in \mathbb{N} \text {. }
$$

Arguing by contradiction, we assume that there exists $m \in \mathbb{N}$ such that

$$
\frac{1}{2} d\left(x_{m}, T x_{m}\right) \geq d\left(x_{m}, x^{*}\right) \text { and } \quad \frac{1}{2} d\left(T x_{m}, T^{2} x_{m}\right) \geq d\left(T x_{m}, x^{*}\right)
$$

Now from $(8)$ and $\left(F_{1}\right)$, we have

$$
d\left(T x_{m}, T^{2} x_{m}\right)<d\left(x_{m}, T x_{m}\right)
$$

It follows from (23) and (24) that

$$
\begin{aligned}
d\left(x_{m}, T x_{m}\right) & \leq d\left(x_{m}, x^{*}\right)+d\left(x^{*}, T x_{m}\right) \\
& \leq \frac{1}{2} d\left(x_{m}, T x_{m}\right)+\frac{1}{2} d\left(T x_{m}, T^{2} x_{m}\right) \\
& <\frac{1}{2} d\left(x_{m}, T x_{m}\right)+\frac{1}{2} d\left(x_{m}, T x_{m}\right) \\
& =d\left(x_{m}, T x_{m}\right),
\end{aligned}
$$

which is a contradiction. Hence (22) holds.

Suppose, now, part (I) of (22) is satisfied and $d\left(x^{*}, T x^{*}\right)>0$. Note from (21) there exists $N_{1} \in \mathbb{N}$ such that $d\left(T x_{n}, T x^{*}\right)=d\left(x_{n+1}, T x^{*}\right)>0$ for $n \geq N_{1}$. Then from our assumption (with $n \geq N_{1}$ ) we have

$$
\begin{aligned}
\tau+F\left(d\left(x_{n+1}, T x^{*}\right)\right)= & \tau+F\left(d\left(T x_{n}, T x^{*}\right)\right) \\
\leq & F\left(\operatorname { m a x } \left\{d\left(x_{n}, x^{*}\right), d\left(x_{n}, T x_{n}\right), d\left(x^{*}, T x^{*}\right),\right.\right. \\
& \left.\left.\frac{d\left(x_{n}, T x^{*}\right)+d\left(x^{*}, T x_{n}\right)}{4}\right\}\right) \\
\leq & F\left(\operatorname { m a x } \left\{d\left(x_{n}, x^{*}\right), d\left(x_{n}, T x_{n}\right), d\left(x^{*}, T x^{*}\right),\right.\right. \\
& \left.\left.\frac{2 d\left(x_{n}, x^{*}\right)+d\left(x^{*}, T x^{*}\right)+d\left(x_{n}, T x_{n}\right)}{4}\right\}\right) .
\end{aligned}
$$


From (10) and (21), there exists $N_{3} \in \mathbb{N}$ (with $N_{3} \geq N_{1}$ ) such that for all $n \geq N_{3}$

$$
\begin{aligned}
& \max \left\{d\left(x_{n}, x^{*}\right), d\left(x_{n}, T x_{n}\right), d\left(x^{*}, T x^{*}\right), \frac{2 d\left(x_{n}, x^{*}\right)+d\left(x^{*}, T x^{*}\right)+d\left(x_{n}, T x_{n}\right)}{4}\right\} \\
& =d\left(x^{*}, T x^{*}\right) .
\end{aligned}
$$

Now from (25), we get

$$
\tau+F\left(d\left(x_{n+1}, T x^{*}\right)\right) \leq F\left(d\left(x^{*}, T x^{*}\right)\right), \quad \forall n \geq N_{3} .
$$

From (F3') and (21), by taking the limit as $n \rightarrow \infty$ in (26), we obtain

$$
\tau+F\left(d\left(x^{*}, T x^{*}\right)\right) \leq F\left(d\left(x^{*}, T x^{*}\right)\right),
$$

which is a contradiction.

Now suppose part (II) of (22) is true, and $d\left(x^{*}, T x^{*}\right)>0$. Note from (21) there exists $N_{2} \in \mathbb{N}$ such that $d\left(T\left(T x_{n}\right), T x^{*}\right)=d\left(x_{n+2}, T x^{*}\right)>0$ for $n \geq N_{2}$. Then from our assumption (with $n \geq N_{2}$ ) we have

$$
\begin{aligned}
\tau+F\left(d\left(x_{n+2}, T x^{*}\right)\right)= & \tau+F\left(d\left(T^{2} x_{n}, T x^{*}\right)\right) \\
\leq & F\left(\operatorname { m a x } \left\{d\left(T x_{n}, x^{*}\right), d\left(T x_{n}, T^{2} x_{n}\right), d\left(x^{*}, T x^{*}\right),\right.\right. \\
& \left.\left.\frac{d\left(T x_{n}, T x^{*}\right)+d\left(x^{*}, T^{2} x_{n}\right)}{4}\right\}\right) \\
\leq & F\left(\operatorname { m a x } \left\{d\left(T x_{n}, x^{*}\right), d\left(T x_{n}, T^{2} x_{n}\right), d\left(x^{*}, T x^{*}\right),\right.\right. \\
& \left.\left.\frac{2 d\left(T x_{n}, x^{*}\right)+d\left(x^{*}, T x^{*}\right)+d\left(T x_{n}, T^{2} x_{n}\right)}{4}\right\}\right) \\
= & F\left(\operatorname { m a x } \left\{d\left(x_{n+1}, x^{*}\right), d\left(x_{n+1}, T x_{n+1}\right), d\left(x^{*}, T x^{*}\right),\right.\right. \\
& \left.\left.\frac{2 d\left(x_{n+1}, x^{*}\right)+d\left(x^{*}, T x^{*}\right)+d\left(x_{n+1}, T x_{n+1}\right)}{4}\right\}\right) .
\end{aligned}
$$

From (10) and (21), there exists $N_{4} \in \mathbb{N}$ (with $N_{4} \geq N_{2}$ ) such that for all $n \geq N_{4}$.

$$
\begin{aligned}
& \max \left\{d\left(x_{n+1}, x^{*}\right), d\left(x_{n+1}, T x_{n+1}\right), d\left(x^{*}, T x^{*}\right), \frac{2 d\left(x_{n+1}, x^{*}\right)+d\left(x^{*}, T x^{*}\right)+d\left(x_{n+1}, T x_{n+1}\right)}{4}\right\} \\
& \quad=d\left(x^{*}, T x^{*}\right) .
\end{aligned}
$$

From (27), we get

$$
\tau+F\left(d\left(x_{n+2}, T x^{*}\right)\right) \leq F\left(d\left(x^{*}, T x^{*}\right)\right), \quad \forall n \geq N_{4} .
$$

From (F3) and (21), taking the limit as $n \rightarrow \infty$ in (28), we obtain

$$
\tau+F\left(d\left(x^{*}, T x^{*}\right)\right) \leq F\left(d\left(x^{*}, T x^{*}\right)\right),
$$

which is a contradiction. Hence, we conclude that $x^{*}$ is a fixed point of $T$. 
Definition 2.3 Let $(X, d)$ be a metric-like space. A mapping $T: X \rightarrow X$ is said to be a conditionally $F$-contraction of type (B) if there exist $F \in \mathfrak{F}$ and $\tau>0$ such that, for all $x, y \in X$ with $d(T x, T y)>0$,

$$
\frac{1}{2} d(x, T x)<d(x, y) \quad \Rightarrow \quad \tau+F(d(T x, T y)) \leq F(\max \{d(x, y), d(x, T x), d(y, T y)\}) .
$$

Definition 2.4 Let $(X, d)$ be a metric-like space. A mapping $T: X \rightarrow X$ is said to be a conditionally $F$-contraction of type (C) if there exist $F \in \mathfrak{F}$ and $\tau>0$ such that, for all $x, y \in X$ with $d(T x, T y)>0$,

$$
\frac{1}{2} d(x, T x)<d(x, y) \quad \Rightarrow \quad \tau+F(d(T x, T y)) \leq F(d(x, y)) .
$$

Theorem 2.5 Let $(X, d)$ be a complete metric-like space. If $T$ is a conditionally $F$ contraction of type (B), then $T$ has a fixed point $x^{*} \in X$.

Proof Following the proof in Theorem 2.2, we easily conclude the result.

Theorem 2.6 Let $(X, d)$ be a complete metric-like space. If $T$ is a conditionally $F$ contraction of type $(\mathrm{C})$, then $T$ has a fixed point $x^{*} \in X$.

Proof It can easily be derived by following the proof in Theorem 2.2 .

Next we consider an example to illustrate our main result. We consider a mapping $T$ which is not continuous, so not an $F$-contraction but it is a conditionally $F$-contraction of type $(C)$.

Example 2.7 Consider $X=\{0,1,2\}$. Let $d: X \times X \rightarrow[0, \infty)$ be a mapping defined by

$$
\begin{aligned}
& d(0,0)=d(1,1)=0, \quad d(2,2)=5 / 2, \\
& d(0,2)=d(2,0)=2, \quad d(1,2)=d(2,1)=3, \\
& d(0,1)=d(1,0)=3 / 2 .
\end{aligned}
$$

It is clear that $d$ is a metric-like. Note that $d(2,2) \neq 0$, so $d$ is not a metric. Clearly, $(X, d)$ is a complete metric-like space. Let $T: X \rightarrow X$ be given by

$$
T 0=0=T 1 \quad \text { and } \quad T 2=1 .
$$

Suppose that $F(\alpha)=\frac{-1}{\alpha}+\alpha \in \mathfrak{F}$ and $\tau \in(0,1 / 2)$. Since $T$ is not continuous, $T$ is not a $F$-contraction by Remark 1.3 .

We will consider the inequality

$$
\frac{1}{2} d(x, T x)<d(x, y),
$$

where $x, y \in X$ with $d(T x, T y)>0$ and the inequality

$$
\tau+F(d(T x, T y)) \leq F(d(x, y))
$$

for those $x, y \in X$ with $d(T x, T y)>0$ which satisfy (31). 
Case 1: Let $x=0$. Now $d(T 0, T 0)=d(T 0, T 1)=d(0,0)=0$ so we need only consider $y=2$ in (31) and (32). Now (31) is true since

$$
\frac{1}{2} d(0, T 0)=0<d(0,2)=2
$$

Also note

$$
d(T 0, T 2)=d(0,1)=\frac{3}{2}<2=d(0,2)
$$

Now inequality (32) is satisfied since

$$
\begin{aligned}
\tau+F(d(T 0, T 2)) & =\tau-\frac{1}{d(T 0, T 2)}+d(T 0, T 2) \\
& \leq \tau-\frac{1}{d(0,2)}+\frac{3}{2} \leq \frac{1}{2}-\frac{1}{d(0,2)}+\frac{3}{2} \\
& =-\frac{1}{d(0,2)}+2=-\frac{1}{d(0,2)}+d(0,2)=F(d(0,2))
\end{aligned}
$$

Case 2: Let $x=1$. Now $d(T 0, T 1)=d(T 1, T 1)=d(0,0)=0$ so we need only consider $y=2$ in (31) and (32). Now (31) is true since

$$
\frac{1}{2} d(1, T 1)=0<d(1,2)=3 .
$$

Also note

$$
d(T 1, T 2)=d(0,1)=\frac{3}{2}<3=d(1,2) .
$$

Now inequality (32) is satisfied since

$$
\begin{aligned}
\tau+F(d(T 1, T 2)) & =\tau-\frac{1}{d(T 1, T 2)}+d(T 1, T 2) \\
& \leq \tau-\frac{1}{d(1,2)}+\frac{3}{2} \leq \frac{1}{2}-\frac{1}{d(1,2)}+\frac{3}{2}=-\frac{1}{d(1,2)}+2 \\
& \leq-\frac{1}{d(1,2)}+3=-\frac{1}{d(1,2)}+d(1,2)=F(d(1,2))
\end{aligned}
$$

Case 3: Let $x=2$. Now $d(T 2, T 2)=0$ so we need only consider the case $y \in\{0,1\}$. Note $d(T 2, T 1)=d(1,0)>0, d(T 2, T 0)=d(1,0)>0$, and also note

$$
\frac{1}{2} d(2, T 2)=\frac{1}{2} d(1,2)=\frac{3}{2}
$$

and

$$
d(2,0)=2, \quad d(2,1)=3,
$$

so (31) holds. 
Note

$$
d(T 2, T 0)=d(1,0)=\frac{3}{2}<2=d(2,0)
$$

and

$$
d(T 2, T 1)=d(1,0)=\frac{3}{2}<3=d(2,1),
$$

so

$$
\tau+F(d(T 2, T 0)) \leq F(d(2,0))
$$

follows as in Case 1 and

$$
\tau+F(d(T 2, T 1)) \leq F(d(2,1))
$$

follows as in Case 2.

Hence $T$ is a conditionally $F$-contraction of type (C). It is clear that 0 is the fixed point of $T$.

\section{Consequences}

In $[14,20]$, Matthews introduced the notion of partial metric, a generalization of a metric, as a part of the study of denotational semantics of dataflow networks.

Definition 3.1 (See [14]) Let $X$ be a non-empty set. A mapping $p: X \times X \rightarrow \mathbb{R}_{0}^{+}$is said to be a partial metric on $X$ if for all $x, y, z \in X$ the following conditions are satisfied:

$\left(\mathrm{p}_{1}\right) x=y$ if and only if $p(x, x)=p(x, y)=p(y, y)$;

$\left(\mathrm{p}_{2}\right) \quad p(x, x) \leq p(x, y)$

$\left(\mathrm{p}_{3}\right) p(x, y)=p(y, x)$;

$\left(\mathrm{p}_{4}\right) p(x, z) \leq p(x, y)+p(y, z)-p(y, y)$.

In this case, the pair $(X, p)$ is called a partial metric space (PMS).

Notice that the function $d_{p}: X \times X \rightarrow \mathbb{R}^{+}$defined by $d_{p}(x, y)=2 p(x, y)-p(x, x)-p(y, y)$ satisfies the conditions of a metric on $X$. Each partial metric $p$ on $X$ generates a $T_{0}$ topology $\tau_{p}$ on $X$, whose base is a family of open $p$-balls $\left\{B_{p}(x, \varepsilon): x \in X, \varepsilon>0\right\}$ where $B_{p}(x, \varepsilon)=$ $\{y \in X: p(x, y) \leq p(x, x)+\varepsilon\}$ for all $x \in X$ and $\varepsilon>0$. Consequently, it is easy to consider several topological concepts. A sequence $\left\{x_{n}\right\}$ in the PMS $(X, p)$ converges to the limit $x$ if $p(x, x)=\lim _{n \rightarrow \infty} p\left(x, x_{n}\right)$ and is said to be a Cauchy sequence if $\lim _{n, m \rightarrow \infty} p\left(x_{n}, x_{m}\right)$ exists and is finite. A PMS $(X, p)$ is called complete if every Cauchy sequence $\left\{x_{n}\right\}$ in $X$ converges with respect to $\tau_{p}$, to a point $x \in X$ such that $p(x, x)=\lim _{n, m \rightarrow \infty} p\left(x_{n}, x_{m}\right)$. For more details, see e.g. $[14,20-40]$ and the related references therein.

Lemma 3.2 (See e.g. $[21,22])$ Let $(X, p)$ be a complete PMS. Then

(A) If $p(x, y)=0$ then $x=y$.

(B) If $x \neq y$, then $p(x, y)>0$.

(C) A sequence $\left\{x_{n}\right\}$ is a Cauchy sequence in the PMS $(X, p)$ if and only if it is a Cauchy sequence in the metric space $\left(X, d_{p}\right)$. 
(D) A PMS $(X, p)$ is complete if and only if the metric space $\left(X, d_{p}\right)$ is complete. Moreover,

$$
\lim _{n \rightarrow \infty} d_{p}\left(x, x_{n}\right)=0 \quad \Leftrightarrow \quad p(x, x)=\lim _{n \rightarrow \infty} p\left(x, x_{n}\right)=\lim _{n, m \rightarrow \infty} p\left(x_{n}, x_{m}\right) .
$$

(E) Assume $x_{n} \rightarrow z$ as $n \rightarrow \infty$ in a PMS $(X, p)$ such that $p(z, z)=0$. Then $\lim _{n \rightarrow \infty} p\left(x_{n}, y\right)=p(z, y)$ for every $y \in X$.

Now we derive the analog of Theorem 2.2 in the context of partial metric spaces. In fact, in the following theorem we conclude not only the existence of a fixed point of the given mapping but also the uniqueness.

Theorem 3.3 Let $(X, p)$ be a complete partial metric space and let $T: X \rightarrow X$ be a self-mapping. Suppose that there exist $F \in \mathfrak{F}$ and $\tau>0$ such that, for all $x, y \in X$ with $p(T x, T y)>0$,

$$
\begin{aligned}
& \frac{1}{2} p(x, T x)<p(x, y) \\
& \quad \Rightarrow \quad \tau+F(p(T x, T y)) \leq F\left(\max \left\{p(x, y), p(x, T x), p(y, T y), \frac{p(x, T y)+p(y, T x)}{2}\right\}\right) .
\end{aligned}
$$

Then $T$ has a unique fixed point $x^{*} \in X$.

Proof Since every partial metric space is a metric-like space, we obtain the proof by following the proof in Theorem 2.2. Note that the expression $\frac{p(x, T y)+p(y, T x)}{4}$ in the inequality (3) is replaced by $\frac{p(x, T y)+p(y, T x)}{2}$ in the inequality (34). This difference arises due to assumptions $\left(\mathrm{p}_{2}\right)$ and $\left(\mathrm{p}_{4}\right)$ of partial metric spaces. Hence, taking $\left(\mathrm{p}_{2}\right)$ and $\left(\mathrm{p}_{4}\right)$ into account, following the proof in Theorem 2.2 yields the existence of a fixed point $\left(x^{*} \in X\right)$ of $T$.

We now show the uniqueness of the fixed point of $T$. Suppose there is another fixed point $y^{*} \in X$ of $T$, such that $x^{*} \neq y^{*}$. Thus from Lemma 3.2, we have $p\left(x^{*}, y^{*}\right)>0$. From $\left(\mathrm{p}_{2}\right)$, we have

$$
\frac{1}{2} p\left(x^{*}, T x^{*}\right)=\frac{1}{2} p\left(x^{*}, x^{*}\right)<p\left(x^{*}, x^{*}\right) \leq p\left(x^{*}, y^{*}\right) .
$$

Thus, from $\left(\mathrm{p}_{2}\right)$, we obtain (note $p\left(T x^{*}, T y^{*}\right)=p\left(x^{*}, y^{*}\right)>0$ )

$$
\begin{aligned}
\tau+F\left(p\left(x^{*}, y^{*}\right)\right) & =\tau+F\left(p\left(T x^{*}, T y^{*}\right)\right) \\
& \leq F\left(\max \left\{p\left(x^{*}, y^{*}\right), p\left(x^{*}, T x^{*}\right), p\left(y^{*}, T y^{*}\right), \frac{p\left(x^{*}, T y^{*}\right)+p\left(y^{*}, T x^{*}\right)}{2}\right\}\right) \\
& =F\left(\max \left\{p\left(x^{*}, y^{*}\right), p\left(x^{*}, x^{*}\right), p\left(y^{*}, y^{*}\right), \frac{p\left(x^{*}, y^{*}\right)+p\left(y^{*}, x^{*}\right)}{2}\right\}\right) \\
& \leq F\left(\max \left\{p\left(x^{*}, y^{*}\right), p\left(x^{*}, y^{*}\right), p\left(x^{*}, y^{*}\right) \frac{p\left(x^{*}, y^{*}\right)+p\left(y^{*}, x^{*}\right)}{2}\right\}\right) \\
& =F\left(p\left(x^{*}, y^{*}\right)\right) .
\end{aligned}
$$

This is a contradiction, and hence $x^{*}=y^{*}$. 
The following two theorems can be obtained easily by repeating the steps in the proof of Theorem 3.3.

Theorem 3.4 Let $(X, p)$ be a complete partial metric space and let $T: X \rightarrow X$ be a self-mapping. Suppose that there exist $F \in \mathfrak{F}$ and $\tau>0$ such that, for all $x, y \in X$ with $p(T x, T y)>0$,

$$
\frac{1}{2} p(x, T x)<p(x, y) \quad \Rightarrow \quad \tau+F(p(T x, T y)) \leq F(\max \{p(x, y), p(x, T x), p(y, T y)\}) .
$$

Then $T$ has a unique fixed point $x^{*} \in X$.

Theorem 3.5 Let $(X, p)$ be a complete partial metric space and let $T: X \rightarrow X$ be a self-mapping. Suppose that there exist $F \in \mathfrak{F}$ and $\tau>0$ such that, for all $x, y \in X$ with $p(T x, T y)>0$,

$$
\frac{1}{2} p(x, T x)<p(x, y) \quad \Rightarrow \quad \tau+F(p(T x, T y)) \leq F(p(x, y)) .
$$

Then $T$ has a unique fixed point $x^{*} \in X$.

Remark 3.6 On can also easily conclude that the analog of Theorem 3.3-Theorem 3.5 in the context of metric spaces since each metric space is a partial metric space.

Competing interests

The authors declare that they have no competing interests.

Authors' contributions

All authors contributed equally and significantly in writing this article. All authors read and approved the final manuscript.

Author details

'Department of Mathematics, Atılım University, Incek, Ankara 06836, Turkey. ${ }^{2}$ Nonlinear Analysis and Applied Mathematics Research Group (NAAM), King Abdulaziz University, Jeddah, Saudi Arabia. ${ }^{3}$ Department of Mathematics, King Abdulaziz University, P.O. Box 80203, Jeddah, 21589, Saudi Arabia. ${ }^{4}$ Department of Mathematics, Faculty of Basic Science, University of Bonab, P.O. Box 5551-761167, Bonab, Iran. ${ }^{5}$ School of Mathematics, Statistics and Applied Mathematics, National University of Ireland, Galway, Ireland.

\section{Acknowledgements}

This project was funded by the Deanship of Scientific Research (DSR), King Abdulaziz University, under grant no. (55-130-35-HiCi). The authors, therefore, acknowledge technical and financial support of KAU.

Received: 1 January 2015 Accepted: 3 July 2015 Published online: 23 July 2015

\section{References}

1. Wardowski, D: Fixed point theory of a new type of contractive mappings in complete metric spaces. Fixed Point Theory Appl. 2012, Article ID 94 (2012)

2. Piri, $\mathrm{H}$, Kumam, P. Some fixed point theorems concerning F-contraction in complete metric spaces. Fixed Point Theory Appl. 2014, Article ID 210 (2014). doi:10.1186/1687-1812-2014-210

3. Wardowski, D, Van Dung, N: Fixed points of $f$-weak contractions on complete metric spaces. Demonstr. Math. 1, 146-155 (2014)

4. Suzuki, T: A new type of fixed point theorem in metric spaces. Nonlinear Anal. 71, 5313-5317 (2009)

5. Suzuki, T: Generalized distance and existence theorems in complete metric spaces. J. Math. Anal. Appl. 253, 440-458 (2001)

6. Suzuki, T: Several fixed point theorems concerning-distance. Fixed Point Theory Appl. 2004, 195-209 (2004)

7. Tataru, D: Viscosity solutions of Hamilton-Jacobi equations with unbounded nonlinear terms. J. Math. Anal. Appl. 163, 345-392 (1992)

8. Vályi, I: A general maximality principle and a fixed point theorem in uniform space. Period. Math. Hung. 16, 127-134 (1985)

9. Włodarczyk, K, Plebaniak, R: Quasigauge spaces with generalized quasipseudodistances and periodic points of dissipative set-valued dynamic systems. Fixed Point Theory Appl. 2011, Article ID 712706 (2011)

10. Włodarczyk, K, Plebaniak, P: Kannan-type contractions and fixed points in uniform spaces. Fixed Point Theory Appl. 2011, Article ID 90 (2011) 
11. Włodarczyk, K, Plebaniak, R: Contractivity of Leader type and fixed points in uniform spaces with generalized pseudodistances. J. Math. Anal. Appl. 387, 533-541 (2012)

12. Hitzler, P: Generalized metrics and topology in logic programming semantics. Ph.D thesis, School of Mathematics, Applied Mathematics and Statistics, National University Ireland, University College Cork (2001)

13. Amini-Harandi, A: Metric-like spaces, partial metric spaces and fixed points. Fixed Point Theory Appl. 2012, Article ID 204 (2012). doi:10.1186/1687-1812-2012-204

14. Matthews, SG: Partial metric topology. Research Report 212, Department of Computer Science, University of Warwick (1992)

15. Abdeljawad, T, Karapınar, E, Tas, K: Existence and uniqueness of a common fixed point on partial metric spaces. Appl. Math. Lett. 24, 1900-1904 (2011)

16. Abdeljawad, T, Karapınar, E, Tas, K: A generalized contraction principle with control functions on partial metric spaces. Comput. Math. Appl. 63, 716-719 (2012)

17. Karapınar, E, Erhan, IM: Fixed point theorems for operators on partial metric spaces. Appl. Math. Lett. 24, 1894-1899 (2011)

18. Romaguera, S: Fixed point theorems for generalized contractions on partial metric spaces. Topol. Appl. 159, 194-199 (2012)

19. Karapınar, E, Salimi, P: Dislocated metric space to metric spaces with some fixed point theorems. Fixed Point Theory Appl. 2013, Article ID 222 (2013)

20. Matthews, SG: Partial metric topology. In: Proc. 8th Summer Conference on General Topology and Application. Ann. New York Acad. Sci., vol. 728, pp. 183-197 (1994)

21. Abdeljawad, T, Karapınar, E, Tas, K: Existence and uniqueness of a common fixed point on partial metric spaces. Appl. Math. Lett. 24(11), 1894-1899 (2011)

22. Karapınar, E, Erhan, IM: Fixed point theorems for operators on partial metric spaces. Appl. Math. Lett. 24(11), 1900-1904 (2011)

23. Karapınar, E: Weak $\phi$-contraction on partial contraction. J. Comput. Anal. Appl. 14(2), 206-210 (2012)

24. Karapınar, E, Erhan, ÝM, Ulus, AY: Fixed point theorem for cyclic maps on partial metric spaces. Appl. Math. Inf. Sci. 6(1), 239-244 (2012)

25. Karapınar, E, Samet, B: Generalized $\alpha$ - $\psi$-contractive type mappings and related fixed point theorems with applications. Abstr. Appl. Anal. 2012, Article ID 793486 (2012)

26. Karapınar, E, Sadarangani, K: Berinde mappings in ordered metric spaces. Rev. R. Acad. Cienc. Exactas Fís. Nat., Ser. A Mat. (2014). doi:10.1007/s13398-014-0186-2

27. Aydi, H, Vetro, C, Karapınar, E: On Ekeland's variational principle in partial metric spaces. Appl. Math. Inf. Sci. 9(1), 257-262 (2015)

28. Jleli, M, Karapınar, E, Samet, B: Further remarks on fixed point theorems in the context of partial metric spaces. Abstr. Appl. Anal. 2013, Article ID 715456 (2013)

29. Roldan, A, Martinez-Moreno, J, Roldan, C, Karapınar, E: Multidimensional fixed point theorems in partially ordered complete partial metric spaces under $(\psi, \varphi)$-contractivity conditions. Abstr. Appl. Anal. 2013, Article ID 634371 (2013)

30. Gulyaz, S, Karapınar, E: Coupled fixed point result in partially ordered partial metric spaces through implicit function Hacet. J. Math. Stat. 42(4), 347-357 (2013)

31. Karapınar, E, Romaguera, S: Nonunique fixed point theorems in partial metric spaces. Filomat 27(7), 1305-1314 (2013)

32. Karapınar, E, Erhan, I, Ozturk, A: Fixed point theorems on quasi-partial metric spaces. Math. Comput. Model. 57(9-10), 2442-2448 (2013)

33. Aydi, H, Karapınar, E: A Meir-Keeler common type fixed point theorem on partial metric spaces. Fixed Point Theory Appl. 2012, Article ID 26 (2012)

34. Karapınar, E, Chi, KP, Thanh, TD: A generalization of Ćirić quasi-contractions. Abstr. Appl. Anal. 2012, Article ID 518734 (2012). doi:10.1155/2012/518734

35. Karapınar, E: Generalizations of Caristi Kirk's theorem on partial metric spaces. Fixed Point Theory Appl. 2011, Article ID 4 (2011)

36. Abdeljawad, T, Karapınar, E, Tas, K: A generalized contraction principle with control functions on partial metric spaces Comput. Math. Appl. 63(3), 716-719 (2012)

37. Rus, IA: Fixed point theory in partial metric spaces. An. Univ. Vest. Timişs., Ser. Mat.-Inform. 46(2), 149-160 (2008)

38. Romaquera, S: A Kirk type characterization of completeness for partial metric spaces. Fixed Point Theory Appl. 2010 Article ID 493298 (2010)

39. Cirić, L, Samet, B, Aydi, H, Vetro, C: Common fixed points of generalized contractions on partial metric spaces and an application. Appl. Math. Comput. 218, 2398-2406 (2011)

40. Bukatin, M, Kopperman, R, Matthews, S, Pajoohesh, H: Partial metric spaces. Am. Math. Mon. 116, 708-718 (2009) 